\title{
Relationship of Attachment Styles and Locus of Control among Third Year Girls of Secondary School
}

\author{
Maryam Hazrati ${ }^{1}$, Nasibeh Parvin ${ }^{2}$
}

\section{ABSTRACT}

Background: Attachment is an emotional bonding between child and his mother and quality of this relationship may impact the psychological wellbeing of child in next steps of life. Main purpose of this study was to study the Relation of attachment styles (secure, avoidant, anxious and ambivalent) and locus of control (Internal-External) among third year girls of secondary school in Iran.

Materials and Methods: The Sample of the present research was selected by Random sampling method from 3 educational regions north, center and south of Tehran. The total sample consisted of 305 students. Two questionnaires were used, including revised Adult attachment scale (secure, avoidant and anxious/ambivalent) by Collins and read (1990) and locus of control questionnaire by Julian Rotter (1966-1972). Regarding analysis of Hypothesis, Pearson correlation test and multiple regression were conducted.

Results: The result indicated that secure attachment style maintains no relationship with internal locus of control. While, avoidant attachment style maintain a meaningful positive relation with external locus of Control. No meaningful relation was found between attachment style and locus of control adolescents and their parent's age. A positive meaningful relation was found between adolescents' attachment style and their parent's educational levels. Father's high educational level (MSc, PhD) showed a positive relation with anxious/ambivalent attachment style. Additionally, fathers' low educational level (diploma and lower degrees), showed a positive relation with secure attachment style. The mother's high educational level showed positive relation with anxious ambivalent attachment style. No relation was found between adolescent locus of control and parent's education and parent's job.

Keywords: Attachment styles, Locus of Control, Adolescent

${ }^{1}$ Department of Psychology, University of Alzahra, Tehran, Sherafati St, Iran

${ }^{2}$ Department of Clinical Psychology, University of Tehran, Tehran، Keshavarz Blvd

(C) 2015 I M Hazrati, N Parvin; licensee IJIP. This is an Open Access Research distributed under the terms of the Creative Commons Attribution License (http://creativecommons.org/licenses/by/2.0), which permits unrestricted use, distribution, and reproduction in any Medium, provided the original work is properly cited. 
In developmental psychology, attachment is discussed as specific bonding between child and his main caregiver and child will use caregiver as a shelter in distress times and may show anxiety symptoms while he sense separation. Attachment is an ambivalence connection, a constant emotional bonding between child and caregiver that both of them are effective in marinating the quality of this relationship. Attachment is an emotional bonding between mother and child, which is the insurance of psychological hygiene of an individual. Secure attachment style can be discussed as Children who are securely attached generally become visibly upset when their caregivers leave, and are happy when their parents return. When frightened, these children will seek comfort from the parent or caregiver. Ambivalent/Anxious Attachment When parents or caregivers interact with their children in ways that are inconsistent and unpredictable, the children develop ambivalent/anxious attachment patterns. Attachments researchers describe the behavior of these adults, noting how at times they are nurturing, attuned and respond effectively to their child's distress, while at other times they are intrusive, insensitive or emotionally unavailable. Finally, infants with an Avoidant attachment style do not exhibit distress upon separation and do not seek contact after the caregiver's return (1).

According to development psychology findings, an adolescent is a vital era between childhood and adulthood. Onset of this period can be notified firstly by dramatic physical changes and end of it can be identified as forming a proper mental structure and some social/emotional alteration.

Rotter(2) discussed locus of control for the first time. There to two kind of control: 1.Internal 2.External. Individuals who tend to have internal locus of control are the ones who accept the responsibility of their actions and they refer the result to internal factors. On the contrary, Individuals who put responsibility on external factors rather than themselves tend to have external locus of control(3). According to recent findings, supporting and warm style of parenthood maintain a positive relation with internal locus of control (4). According to recent studies, secure attachment styles have a positive relation with psychological wellbeing of individuals, so this study may help mothers to create a secure attachment style with their children (5). A lot of studies have been conducted regarding attachment styles and mental wellbeing but there are a few studies regarding attachment styles and locus of control in individuals. According to recent studies, individuals with internal locus of control, tend to be more adaptive and have higher social skills. Thus, they have higher successful marriage and they are more effective in their educational process (6).

Main purpose of this study was to study the Relation of attachment styles (secure, avoidant and anxious/ambivalent) and locus of control (Internal-External) among third year girls of secondary school in Iran. 


\section{MATERIALS AND METHODS:}

Current study is a descriptive co relational study. The Sample of the present research was selected through Random Cluster sampling method from 3 educational regions north, center and south of Tehran. Statistical society of this study consisted from $3^{\text {rd }}$ grade of secondary school in city of Tehran between 2004-2005. Collins and Read (1990) gathered demographic data through Revised Adult Attachment Scale (RAAS) (7).

Adult Attachment Scale (AAS) was officially developed in 1990 but built on the earlier work of Hazen \& Shaver (1987) and Levy \& Davis (1988). The scale was developed by decomposing the original9three-prototypical descriptions (Hazen \& Shaver, 1987) into a series of 18 items (8) . The scale consists of 18 items scored on a 5 pointlikert-type scale. It measures adult attachment styles named "Secure", "Anxious" and "Avoidant", defined as:

- Secure = high scores on Close and Depend subscales, low score on Anxiety subscale - Anxious $=$ high score on Anxiety subscale, moderate scores on Close and Depend subscales $\cdot$ Avoidant $=$ low scores on Close, Depend, and Anxiety subscales

The 18 items that compromise the measure are as follows:

- I find it difficult to allow myself to depend on others (Av)

- People are never there when you need them (Av)

- I am comfortable depending on others (S)

- I know that others will be there when I need them (S)

- I find it difficult to trust others completely (Av)

- I am not sure that I can always depend on others to be there when I need them (Ax)

- I do not often worry about being abandoned (S)

- I often worry that my partner does not really love me (Ax)

- I find others are reluctant to get as close as I would like (Ax)

- I often worry my partner will not want to stay with me (Ax)

- I want to merge completely with another person (Ax)

- My desire to merge sometimes scares people away (Ax)

- I find it relatively easy to get close to others (S)

- I do not often worry about someone getting close to me (S)

- I am somewhat uncomfortable being close to others (Av)

- I am nervous when anyone gets too close (Av)

- I am comfortable having others depend on me (S)

- Often, love partners want me to be more intimate than I feel comfortable being(Av)

Reliability and Validity: Collins \& Read (1990) reported Cronbach's alpha coefficients of .69 for Close, .75 for Depend, and .72 for Anxiety. Test-retest correlations for a 2-month period were .68 for Close, .71 for Depend, and .52 for Anxiety (9). 
Locus of control questionnaire: Locus of control is a personality dimension originally described by Julian Rotter (1966). According to Rotter, people vary in regard to how responsible they feel for their own fate. Individuals with an internal locus of control tend to believe that people are responsible for their successes and failures. Conversely, people with a relatively external locus of control tend to attribute successes and failures to luck, chance or fate. The scale you just responded to was developed by Stephen Nowicki and Marshall Duke (1974) in order to remedy some technical problems that were characteristic of the original Rotter (1966) scale. Like the original, it measures one's belief about whether events are controlled internally or externally.

\section{RESEARCH ON THE SCALE}

Reports on test-retest reliability (Chandler, 1976; Nowicki \& Duke, 1974) have yielded very respectable figures (such as .83 over a six-week period). While the original Rotter 91966) scale was plagued by a tendency for subjects to give socially desirable responses, the Nowicki and Duke version seems to have minimized this problem. The validity of the scale has been supported by evidence that it correlates well with the original Rotter scale, and that it is related to other variables in the same way that the original scale was (10).

Locus of control has been related to a wide range of variables. One of the more interesting is race. Generally, Blacks score more toward the external end than do Whites (Duke \&Nowicki, 1972). Presumably, this is because Blacks are more likely to be victims of discrimination wherein they do not get rewards that they feel that they have earned. There is also evidence that external locus of control is related weakly to neuroticism and anxiety. Internal locus of control has been shown to be associated with greater academic achievement.

\section{INTERPRETING YOUR SCORE}

The norms are based on data collected by Nowicki and Duke (1974) for 154 Caucasian college students. Additional studies suggest that Blacks and other ethnic minorities should probably shift the score cutoffs upward by about five points.

Norms

External Score $\quad \mathbf{1 6 - 4 0} \quad$ (more than 1.50 standard deviations above the mean)

Intermediate Score: $\quad 7-15 \quad$ (from 0.75 standard deviations below the mean up to 1.50 standard deviations above the mean)

Internal Score: $\quad$ 0- 6 (more than 0.75 standard deviations below the mean) 
External Scorers: A score above 15 suggests that you have a fairly strong belief that events are beyond your control. In other words, you do not feel that there is much of a connection between your behavior and your outcomes. As discussed in your text, this means that you are relatively less likely than others to take credit for your successes or to take the blame for your failures. Instead, you tend to believe that success and failure are primarily a matter of luck and chance breaks (11).

Intermediate Scorers: A score in this range means that you have inconsistent views about the degree to which you control your own fate. You probably believe that you do control your own fate in some areas of your life, while believing that you have little control in other areas.

Internal Scorers: A score below 7 indicates that you have a firm belief in your ability to influence your outcomes. Your relatively internal score means that you generally do not attribute your successes and failures to good and bad luck or chance factors. Instead, you feel that you can influence the course of what happens to you. As mentioned in Chapter 3 of your text, an internal locus of control is associated with relatively great stress tolerance (12).

\section{FINDINGS:}

In this study, regarding assessing the relationship between attachment styles and locus of control we used Pearson's correlation coefficient and regarding assessing parent's age and education variables (attachment styles, locus of control) we used regression statistical model. According to statistical data on Table no1 it can be discussed that frequency of father's age is as illustrated below:

\begin{tabular}{|l|l|l|}
\hline Level & Frequency & Percentage \\
\hline 30-35 years old & 17 & $5 / 7$ \\
\hline 36-40 years old & 100 & $33 / 8$ \\
\hline 41-45 years old & 95 & $32 / 1$ \\
\hline 46-50 years old & 46 & $15 / 5$ \\
\hline More than 51 & 38 & $12 / 8$ \\
\hline Without answer & 9 & \multicolumn{2}{|c|}{-} \\
\hline Total & 305 & 100 \\
\hline
\end{tabular}


Table No 1: Frequency of Father's age in statistical sample

According to statistical data on Table nol it can be discussed that frequency of mother's age is as illustrated below:

\begin{tabular}{|l|l|l|}
\hline Level & Frequency & Percentage \\
\hline $\mathbf{2 4 - 3 0}$ years old & 20 & $6 / 7$ \\
\hline $\mathbf{3 1 - 3 5}$ years old & 95 & 32 \\
\hline $\mathbf{3 6 - 4 0}$ years old & 104 & 35 \\
\hline 41-45 years old & 53 & $17 / 8$ \\
\hline More than 46 & 25 & $8 / 4$ \\
\hline Without answer & 8 & - \\
\hline Total & 305 & 100 \\
\hline
\end{tabular}

Table No 2: Frequency of Mother's age in statistical sample

Regarding education level of fathers, 214(70.4\%) individuals had low educational level (Diploma and below), 67 (22\%) individual had an average(Upper diploma and Bachelor degree) educational level, 23 individuals (7.6 \%) had upper educational level(Master degree or Upper degrees). With respect to mother's educational level, 245(80.9\%) individuals had low educational level (Diploma and below), 48 (15.8\%) individual had an average (Upper diploma and Bachelor degree) educational level, 10 individuals (1.3\%) had upper educational level (Master degree or Upper degrees).

According to Table No3, it can be discussed that 197(75.8\%) of individuals had internal locus of control and 63 individuals $(24.2 \%)$ had an external locus of control.

\begin{tabular}{|l|l|l|}
\hline Levels & Frequency & Percentage \\
\hline Internal locus of Control & 197 & 75.8 \\
\hline External locus of Control & 63 & 24.2 \\
\hline Without answer & 45 & - \\
\hline Total & 305 & 100 \\
\hline
\end{tabular}

\section{TableNo3 Frequency of Locus of Control}

According to Table No4, frequency of attachment's styles in statistical samples is as mentioned below.

\begin{tabular}{|l|l|l|}
\hline Level & Frequency & Percentage \\
\hline Secure & 13 & 4.6 \\
\hline Avoidant & 169 & 59.7 \\
\hline Anxious & 101 & 35.7 \\
\hline Without Answer & 22 & - \\
\hline Total & 305 & 100 \\
\hline
\end{tabular}


TableNo4 Frequency of Attachment of styles

\begin{tabular}{|c|c|c|c|c|c|c|c|c|}
\hline \multirow{2}{*}{$\begin{array}{l}\text { Attachment } \\
\text { Style/ Locus } \\
\text { of Control }\end{array}$} & \multicolumn{2}{|c|}{ Secure } & \multicolumn{2}{|c|}{ Avoidant } & \multicolumn{2}{|c|}{ Anxious } & \multicolumn{2}{|c|}{ Total } \\
\hline & 莺 & 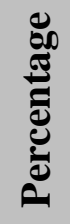 & 忌 & 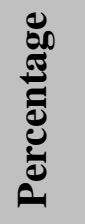 & 冚 & ص્ઠ & 预 & 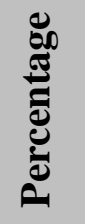 \\
\hline Internal & 7 & 2.9 & 101 & 41.7 & 73 & 30.2 & 181 & 74.8 \\
\hline External & 3 & 1.2 & 43 & 17.8 & 15 & 6.2 & 61 & 25.2 \\
\hline Total & 10 & 4.1 & 144 & 59.5 & 78 & 36.4 & 242 & 100 \\
\hline
\end{tabular}

Table No5 Frequency of Attachment styles and locus of Control

According to Table No5, it can be discussed that majority of individuals $(101,41.7 \%)$ with internal locus of control had an avoidant type of attachment. Furthermore, majority of people $(43,17.8 \%)$ with external locus of control had an avoidant attachment style.

\begin{tabular}{|l|l|l|l|l|}
\hline & $\begin{array}{l}\text { Locus of } \\
\text { Control }\end{array}$ & $\begin{array}{l}\text { Secure } \\
\text { attachment } \\
\text { style }\end{array}$ & $\begin{array}{l}\text { Avoidant } \\
\text { attachment } \\
\text { style }\end{array}$ & $\begin{array}{l}\text { Anxious } \\
\text { Attachment } \\
\text { style }\end{array}$ \\
\hline $\begin{array}{l}\text { Locus of } \\
\text { Control }\end{array}$ & ---- & 0.03 & 0.11 & 0.20 \\
\hline $\begin{array}{l}\text { Secure } \\
\text { attachment } \\
\text { style }\end{array}$ & ---- & --- & 0.24 & -0.13 \\
\hline $\begin{array}{l}\text { Avoidant } \\
\text { attachment } \\
\text { style }\end{array}$ & 0.05 & $0 / 01$ & --- & -0.21 \\
\hline $\begin{array}{l}\text { Anxious } \\
\text { Attachment } \\
\text { style }\end{array}$ & 0.05 & 0.01 & 0.02 & --- \\
\hline
\end{tabular}

Table No6 Correlation Matrix-Studying the relationship of Attachment styles and Locus of Control 
According to Table No6, it can be inferred that in meaningfulness level of $\alpha=0.05$, there is positive relation between locus of control with avoidant and anxious attachment style. Thus, with elevating external locus of control, avoidant and anxious attachment style will be increased. Although, there is not meaningful relationship between locus of control with secure attachment style. According to analyzed data and significance of F(1.43) and in meaningfulness level of $\alpha=$ 0.05 it can be discussed that locus of control cant be forecasted according to parent's age. According to analyzed data and significance of $\mathrm{F}(1.43)$ and in meaningfulness level of $\alpha=0.05$ it can be discussed that locus of control cant be forecasted according to parent's age. With respect to analyzed data and significance of $F(0.44)$ and in meaningfulness level of $\alpha=0.05$ it can be discussed that secure attachment style cant be forecasted according to parent's age. According to analyzed data and significance of $\mathrm{F}(0.16)$ and in meaningfulness level of $\alpha=0.05$ it can be discussed that avoidant attachment style cant be forecasted according to parent's age. According to analyzed data and significance of $F(0.16)$ and in meaningfulness level of $\alpha=0.05$ it can be discussed that anxious attachment style cant be forecasted according to parent's age.

\section{DISCUSSION:}

According to analyzed data of this study, secure attachment style, avoidant; anxious/ambivalent has a relationship with internal/external locus of control. After this study, we reached the result that there is no relation between secure attachment style and internal locus of control and this is against of research's hypothesis. A lot of studies accept this hypothesis and they show positive meaningful relationship between secure attachment style and internal locus of control $(13,14,15)$. Devila (16) assessed the concept that does attachment's style change during life time coarse. The results showed that attachment style may change during lifetime and this change may differ between different people. A second hypothesis was about relationship of avoidant attachment style and external locus of control. According to statistical data, there is a positive relationship between avoidant attachment style and external locus of control. Correlation rate in $(\alpha=0.05)$ is $\mathrm{r}=0.11$ and based on former studies in order to confirm the hypothesis of this study we can mention study conducted by Jenice Kennedy(17). In his study he discussed that students with insecure attachment style assess the positive events as external, inconsistent and they assess negative events as internal, consistent and general. In another studies(18), the results were against current results. In that study, Chinese intern teachers assessed events based on focusing more on successful events rather than failures. Based on researches, people with external locus of control tend to experience more social, educational and occupational opportunities and they surrender themselves more quickly to adverse events. They demonstrate aggressive and irritable attitudes toward social pressures. Based on third hypothesis, Anxious/ambivalent attachment style maintains a relationship with external locus of control. After assessing this hypothesis, this result came out that there is positive relationship between anxious/ambivalent style and external locus of control. Result of this study is consistent with the result of the study conducted by Kennedy (19). In their study the reached this result that students tend to assess the positive 
events as external, inconsistent and special and vice versa. One of the limitations of this study is lack of access toward simple test for youths, lack of former history regarding this subject. And it would be better to conduct this study by interview rather than questionnaire. It would be better to conduct this study in bigger samples. Because each society tend to possess specific cultural background, it would be better to mention religious beliefs in questionnaire regarding locus of control.

\section{ACKNOWLEDGMENT:}

Authors of this study are using this opportunity to express their gratitude to everyone who supported them throughout the course of this study.

\section{REFERENCE:}

Bartholomew. K (1990), Avoidance of Intimacy, An Attachment Perspective. Jurnal of Social \& Personality Relation Ship, 7, 141 - 178.

Bartholomew. K (1990), Avoidance of Intimacy, An Attachment Perspective. Jurnal of Social \& Personality Relation Ship, 7, 141 - 178.

Bee, Helen, (2000), The Developing Child Book, Ninth Edition Copyright (2000) by Allen \& Bacon. Apearson Education Company.

Bee, Helen, (2000), The Developing Child Book, Ninth Edition Copyright (2000) by Allen \& Bacon. Apearson Education Company.

Beyer, Shifrle. B \& Hester, Colleen, (1996), Shame and the Realtion of thoughts: Astudy of their Relation Ship to Attachment, Main Menu JPBS (1996) Contents.

Beyer, Shifrle. B \& Hester, Colleen, (1996), Shame and the Realtion of thoughts: Astudy of their Relation Ship to Attachment, Main Menu JPBS (1996) Contents.

Brennan, Kelley, A. Shaver, Philip, R (Oct 1993), Attachment Styles and Personality Disorder, Their Connections to Each Other and to Parental Death, and Perception of Parental Cargiving, JouenL of Personality (oct 98) vol, 66 Issues, P 835, 44 p.

Brennan, Kelley, A. Shaver, Philip, R (Oct 1993), Attachment Styles and Personality Disorder, Their Connections to Each Other and to Parental Death, and Perception of Parental Cargiving, JouenL of Personality (oct 98) vol, 66 Issues, P 835, 44 p. 
Broemer, Philop, Blume, Melanie (Sep 2003), Self views in close Relation Ships: The Influence of Attachment styles British Journal of social psychology sep 2003. vol 42, Jssue 3, P 445, $16 \mathrm{p}$.

Broemer, Philop, Blume, Melanie (Sep 2003), Self views in close Relation Ships: The Influence of Attachment styles British Journal of social psychology sep 2003. vol 42, Jssue 3, P 445, $16 \mathrm{p}$.

Cole, Michael, Cole, sheilar, (2001), The Development of children Fourth Edition. Uthed New Yourk: Worth Publishers.

Cole, Michael, Cole, sheilar, (2001), The Development of children Fourth Edition. Uthed New Yourk: Worth Publishers.

Collins, N. L., \& Read, S. J. (1990). Adult attachment, working models, and relationship quality in dating couples. Journal of Personality and Social Psychology, 58(4), 644-663.

Eagan, Cristina, E (2003), Rochester Institade of Technology www. Personality Research. org / Paper / Eaqgan, htm.

Eagan, Cristina, E (2003), Rochester Institade of Technology www. Personality Research. org / Paper / Eaqgan, htm.

Gentzler, Amyl and Akems, Kathryn (2006), Adult Attachment and Memory of Emotional Reactions to negative and Positive Events. George Washangton University, Washongton, Dc, USA, Pablisher: psychology press, part of the taylor\& Francis Group, Issue: volume 20, Number 1, January 2006, page 20 - 42.

Gentzler, Amyl and Akems, Kathryn (2006), Adult Attachment and Memory of Emotional Reactions to negative and Positive Events. George Washangton University, Washongton, Dc, USA, Pablisher: psychology press, part of the taylor\& Francis Group, Issue: volume 20, Number 1, January 2006, page 20 - 42.

Hazan, C \& shave, P (1987), Romantic Love Conceptualized as an Attachment Process, Journal of Personality and social psychology. vol, 52, p $511-524$. 